\title{
Comparisons of the physicochemical and functional properties of commercially and traditionally processed sago starch
}

\author{
M.Mustafa Kamal ${ }^{1}$, R.Baini ${ }^{1}$,a , S.Mohamaddan ${ }^{2}$, A.R.Henry Ragai ${ }^{2}$, L. Soh Fong ${ }^{1}$, N. Abdul Rahman ${ }^{1}$, N. Mili ${ }^{1}$, S.N.L.Taib ${ }^{3}$, \\ A.K.Othman ${ }^{4}$, M.O. Abdullah ${ }^{1}$ \\ ${ }^{1}$ Department of Chemical Engineering and Energy Sustainability, Universiti Malaysia Sarawak, 94300 Kota Samarahan, Sarawak, Malaysia \\ ${ }^{2}$ Department of Mechanical and Manufacturing Engineering, Universiti Malaysia Sarawak, 94300 Kota Samarahan, Sarawak, Malaysia \\ ${ }^{3}$ Department of Civil Engineering, Universiti Malaysia Sarawak, 94300 Kota Samarahan, Sarawak, Malaysia \\ ${ }^{4}$ Department of Electrical and Electronic Engineering, Universiti Malaysia Sarawak, 94300 Kota Samarahan, Sarawak, Malaysia
}

\begin{abstract}
Commercial sago starch was obtained from nearby supermarket while traditional sago starch (lemantak) was obtained from local wet-market. In this study, the physicochemical (moisture content, colour, particle size and microstructure) and functional properties (FT-IR spectrometer) of both types of starch were compared. Traditional sago starch (lemantak) exhibits moisture content two times higher than the commercial sago starch. Providing that commercial sago flour has been bleached in the factory, its LAB value also shows higher value than lemantak. Moreover, the particle size of sago flour is also smaller than lemantak, as the effect of multiple-refining in the factory. Meanwhile, the microstructural analysis shows significant difference that is cluster-form-granule in lemantak and disassociated-form-granule in commercial sago flour, which proof that commercial sago flour has been in an extensive process. Finally, the FT-IR results indicated that both sago flour and lemantak has similar spectrometer patterns but differ in the peak intensities, which also indicates the changes in functional properties of sago flour. Results obtained here show that the modern processing equipment as well as the chemical and drying treatment in factory, had led to the loss in some of the purity and functional characteristic in sago starch.
\end{abstract}

\section{Introduction}

Sago starch, derives from the stem of sago palm (Metroxylon sagu) or commonly called as "rumbia"; a tropical plant with huge trunk that may reach height up to $25 \mathrm{~m}$ and a diameter of $40 \mathrm{~cm}$; with pinnate-leaves up to 9 $\mathrm{m}$ long; though can tolerate wet-swampy lands such as peat soil (flood-immuned); however, it reaches commercial maturity after 9 to 12 years of planting (Karim, Tie, Manan, \& Zaidul, 2008). According to Singhal et al. (2008), sago palm has been known as the highest in productivity among the starchy crops in the world (250kg per palm) and also considered as the 'starch crop of the 21 st century' by many scientists, as it is economically acceptable, environmentally friendly, and it promotes a socially stable agroforestry system. Sago starch contains mainly carbohydrate, which is higher than rice and wheat flour; therefore, it has becomes the staple food since ancient times, It is an important raw materials in food industry, especially in Asian region.

In the food industry level, it is predicted that demand of sago in the future will increase as it has becomes an important raw food material (Articles \& Issues, 2016). Malaysia is one of the world's leading sago producer, while Sarawak is the largest sago-growing areas in Malaysia. Until year 2000, there are 21 modern sago processing plants all around Sarawak (Palm, 2016). In

\footnotetext{
a Corresponding author: ruby@feng.unimas.my
}

addition to sago industry in Sarawak, it is the only state in Malaysia known to produce sago starch both commercially with modern techniques and traditionally for local needs (Shin \& Collins, 2015). However, these modern sago processing plants had slowly wiped-out the production of traditional sago starch called "lemantak", a wet-type sago flour (Palm, 2016). This may be due to the low quality standards of 'lemantak' produced by local people. The raw material of both materials is the same but 'Lemantak' that is mixed with warm water will produce certain viscosity, which cannot be obtained using the commercial sago flour. This characteristic of 'lemantak' making it becomes favourable than the commercial sago flour among users for certain application. Sago flour is not only used as food, but also used in the processing of glue cosmetics. Hence, understanding the characteristics of sago flour, which may be influenced by the processing steps, can be important that will determine its appropriate applications.

The principles and methods in commercial sago processing are quite similar with the methods used in traditional level, but differing in the scale of operation and drying stage. The commercial sago flour manufacturer needs to meet the Malaysian standard for food product, therefore, some technique's modification as well as new technologies had been adapted in sago processing (Karim et al., 2008). In brief, the processing of sago started by feeding a segment of sago log into a slicer to separate 
between pith and bark. Then, the debarked section is fed into a mechanical rasper to produce finer pieces which are then fed in hammer mill via conveyor belt. The resulting starch slurry which still containing coarse fibre, is made to pass through a series of centrifugal sieves. Further purification is still needed by separation in a nozzle separator through sieve bends, as well as a series of cyclone separators, to obtain very pure starch. Most importantly, dewatering of starch is carried out using a rotary vacuum drum dryer followed by hot air drying (Karim et al., 2008). In addition, for wider acceptance, additional processing efforts have been developed, such as the production of noodles, edible film, sago pearls, bread and biscuits (Bantacut, 2014).

On the other hand, in traditional method of starch extraction, 'skinning' of the pith is made manually before chopping the pith and grating it into material resembling sawdust. The pith are then kneaded with water and filtered through sieves to extract the relatively large $(20-60 \mathrm{~lm})$ starch granules. After been subjected to several washings and strainings, and the starch milk is allowed to run into troughs. The starch settles in the troughs, which is subsequently sun- or kiln-dried (Singhal et al., 2008). The experiences of local people from Sarawak in consuming sago have proven that sago, when preparing from the traditional process has wide utilization and taste even greater than the commercially processed sago flour. For instances, sago starch has been consumed by mixing hot water and stirring to form dough called 'linut', which is then directly eaten with hot and spicy-protein based side dishes. Further instances of this is, lemantak can be used to make sago pancake or so called as 'tumpik', a baked starch cake, mix with shredded coconut, and top with protein-based food such as fish and prawn.

Interestingly, the compositions of sago is highly beneficial as it has low calorie and fat content which is good for diet; low protein content, therefore, are casein and gluten-free, which is good for gluten-allergic people; low glycemix index, which means suitable for diabetic people as it does not raise blood glucose levels immediately; and also as a resistant starch, sago can prevent the risk of constipation and colon cancer (Articles \& Issues, 2016). For this reason, development of sago processing is necessary by upgrading the productivity and quality of lemantak, which consequently not only can give opportunity to home industry to grow, but also indirectly can give economic impact to the farmers. Furthermore, lemantak can be considered as the best choice to have the fully benefit of sago starch as it has not goes through any heavy-treatment during processing that is suspected to change some of the physicochemical and functional properties of sago starch. This work presents the comparison of the physicochemical and functional properties of commercially and traditionally processed sago starch. The way it is processed affect its characteristics, and in the future, it may become the interest of industry to upgrade the traditional process for commercial production of 'lemantak'. Sarawak is the largest producer of sago flour in Malaysia, meaning there is opportunity for the local people who produced 'lemantak' to generate income.

\section{Materials and Methods}

\subsection{Sago starch sample preparation}

Commercial sago flour, a product from S.G. Trading, Kuching, Sarawak; branded as 'Tepung Sagu Cap Bunga Daffodil'; was bought from local supermarket in Samarahan, Sarawak.

Meanwhile, traditional sago flour, 'lemantak' was bought from local wet-market in Samarahan, Sarawak; however, was processed from Sebuyau; a rural area which is located about 2 hours drive from Samarahan.

\subsection{Physicochemical properties}

\subsubsection{Moisture content}

The determination of moisture content in sago flour and lemantak were analysed by drying $3 \mathrm{~g}$ of sample in gravity oven at $105^{\circ} \mathrm{C}$ until constant weight according to the AOAC, 2000 standard method. The moisture content was calculated in drying basis formula;

$$
\mathrm{mc}=\frac{\mathrm{M}_{\mathrm{i}}-\mathrm{M}_{\mathrm{t}}}{\mathrm{M}_{\mathrm{i}}} \times 100 \%
$$

Where $\mathrm{M}_{\mathrm{i}}$ and $\mathrm{M}_{\mathrm{t}}$ are the initial mass of sample (g) and the mass of sample $(\mathrm{g})$ at a time $(\mathrm{t})$.

\subsubsection{Colour analysis}

An analysis of colour was carried out manually using Matlab software which can measure the pixel data of samples image in RGB value. The RGB values were then converted into CIE-L*ab value by using a RGB-to-Lab converter program available from the internet at http://colormine.org/convert/rgb-to-lab. In addition, ' $\mathrm{L}$ ', represents lightness, "a" represents redness $(+)$ or greenness (-), and " $b$ " represents yellowness $(+)$ or blueness (-). Whiteness index were calculated according to [6].

$$
\mathrm{WI}=100-\sqrt{ }(100-\mathrm{L})^{2}+\mathrm{a}^{2}+\mathrm{b}^{2}
$$

\subsubsection{Scanning Electron Microscopy}

Granules morphology was examined using a scanning electron microscope (SEM). A thin layer of starch granule was mounted on a specimen holder; and the specimen holder was loaded in a sputter coater. Once metalized, the sample was viewed under a scanning electron microscopy (JSM-6701F) supplied by the JEOL Company Limited, Japan. The captured images were printed and saved. All optical measurements were performed at room temperature under ambient conditions.

\subsubsection{Particle size distribution}


The mean size distribution of sago flour and lemantak were measured by using CILAS 1090 Laser Particle Size Analyzer at room temperature. Deionized water was used as the medium for wet size measurement of flours. Sonis measurements were performed to avoid the aggregatation of flours.

\subsection{Functional properties}

\subsubsection{FT-IR}

Fourier transform infrared (FT-IR) spectroscopy was used to evaluate structural differences in the samples. The infrared spectra of the commercial and traditional sago starch were recorded on a Shimadzu Fourier Transform Infrared Spectroscopy (FTIR) 81001 Spectrophotometer. An appropriate amount of starch powder was pressed into a crystal window and the samples were analysed with a resolution of $4 \mathrm{~cm}^{-1}$ and average scanning time of $1 \mathrm{~min}$. Furthermore, the spectral resolution range of scan was 4000 to $400 \mathrm{~cm}^{-1}$ (mid-infrared region) with ATR mode being utilized. The obtained spectra were transferred into a data analysis package. All optical measurements were performed at room temperature under ambient conditions.

\section{Results and Discussion}

\subsection{Moisture Content}

Results obtained from the moisture content experiment show that commercial sago flour exhibit $11.46 \%$ of moisture content per dry basis. The value meet the Malaysian Standard (MS470 1992) requirement for edible sago starch, which stated that the maximum moisture content is $13 \%$. In addition, edible sago starch was defined as fine powder-starch derived from the trunk of sago palm through the process of extraction and purification. However, it should be noted that the starch produced by small factories is usually vary in term of quality including the moisture content; in fact, some often being spoilt through microbial activity [5]. On the other hand, the content of moisture in lemantak is $38.8 \%$, which is significantly three times higher than sago flour. Karim et al. (2008) stated that lemantak is a low-quality starch; produced as the effect of inefficient extraction and processing method; far from international market requirement [1]. However, in local market, it has been understood that high moisture content is related to the local demand especially to make the 'linut'-a meal cooked by mixing lemantak and hot boiling water, which need certain level of consistency.

\subsection{Colour}

The L*, a* and $b^{*}$ characteristic of commercial sago flour and traditional lemantak are shown in Table 1. The colour characteristics of lemantak samples are all in the same agreement of values: $L^{*}$ (below 80 ), a* (1.5-4.5), and $b^{*}$ (9-16.5). The result showed that lemantak were not white, provided that it has low $\mathrm{L}^{*}$ value, less red, provided that it has low a* value; but it were yellow, provided that it has significantly high $b^{*}$ value. In fact the average value of whiteness was 60.21. According to Aboubakar et al., (2008), the variation in $b^{*}$ value among samples may be attributes to the amount of carbohydrate and proteins content in the starch [7]. Both carbohydrate and proteins play an important role in the development of nonenzymatic browning in starch. However, there are also another factors that may affected color development of starch such as the presence of polyphenol compound and the cleanliness during washing step.

Table 1. The colour of commercial sago flour and traditional lemantak in triplicates as plotting randomly in Matlab software.

\begin{tabular}{|c|c|c|c|l|}
\hline \multirow{4}{*}{$\begin{array}{c}\text { Sample } \\
\text { Commercial } \\
\text { sago flour }\end{array}$} & 84.56 & 0.004 & -0.009 & 84.82 \\
\cline { 2 - 5 } & 87.05 & 0.005 & -0.009 & 87.05 \\
\cline { 2 - 5 } & 79.91 & -0.01 & 1.11 & 79.88 \\
\hline \multirow{2}{*}{$\begin{array}{c}\text { Traditional } \\
\text { lemantak }\end{array}$} & 49.69 & 4.004 & 16.19 & 46.99 \\
\cline { 2 - 5 } & 60.00 & 2.86 & 15.26 & 57.09 \\
\cline { 2 - 5 } & 78.72 & 1.88 & 9.69 & 76.54 \\
\hline
\end{tabular}

In contrast, the colour characteristics of commercial sago flour showed that the flour were white, as it showed high $\mathrm{L}^{*}$ value; neither red nor yellow, as it showed very small $a^{*}$ and $b^{*}$ value. In fact the average value for the whiteness were 83.92. It should be noted that commercial sago starches have the lowest whiteness among industrial starches, which accounts for the lower price. Therefore, in order to increase the whiteness property of the starch, several chemicals were added during the manufacturing process of the starch. According to Ranjith \& Balakrishnan (2015), the residue of the chemicals present in the starch will cause several side effects in human beings [8].

\subsection{Microstructure}

Scanning electron micrograph showed that lemantak has an oval shape of diameter $50 \mu \mathrm{m}$, in agreement with most of the previous study which stated that native starch has oval, spherical and irregularly shaped granules with 6-60 $\mu \mathrm{m}$ [9]. Figures 1(a) showed that traditionally processed sago starch, lemantak, are associated as cluster or compound. Furthermore, in Figure 1 (b) and (c), lemantak show the uniformity in granular shape as the amylose and amylopectin inside the granules are tightly packed. The aggregation is a natural property for native starch, hence shows that lemantak's property is much closed to native starch.

Scanning electron micrographs commercially processed sago flour are shown in Fig. 2. Processing effected 
granule's association due to extraction that has been done in an alkaline solution has known to disassociate sago starch granules, as shown in Figure 2(a). Sago flour is refined, purified or slightly bleached by oxidation with small quantities of hypochlorites $(0.25-6 \%$ chlorine on dry basis). Ranjith \& Balakrishnan (2015) had warned that the chemicals added to bleach sago flour, may cause side effects to human being [9]. Figure 2(b) and (c) clearly showed granules that formed into an aggregated mass comprising of several small granules; in fact, some of the granulars appearance totally disappears.

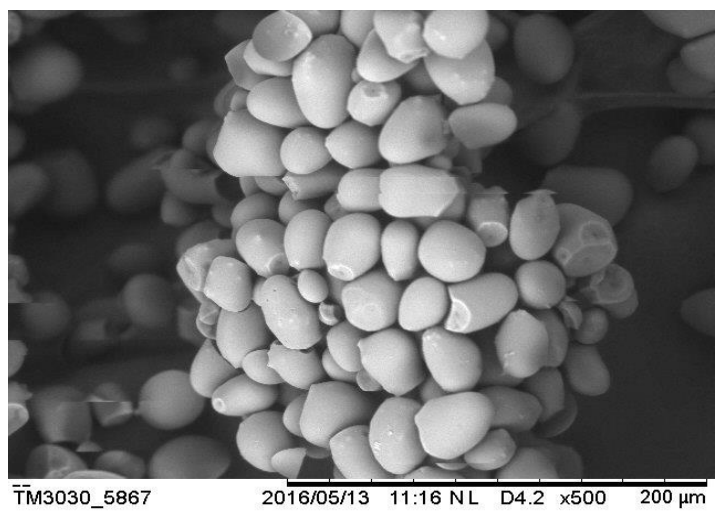

(a)

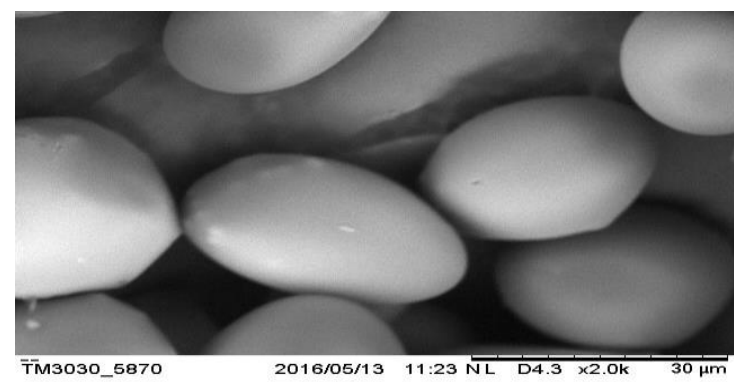

(b)

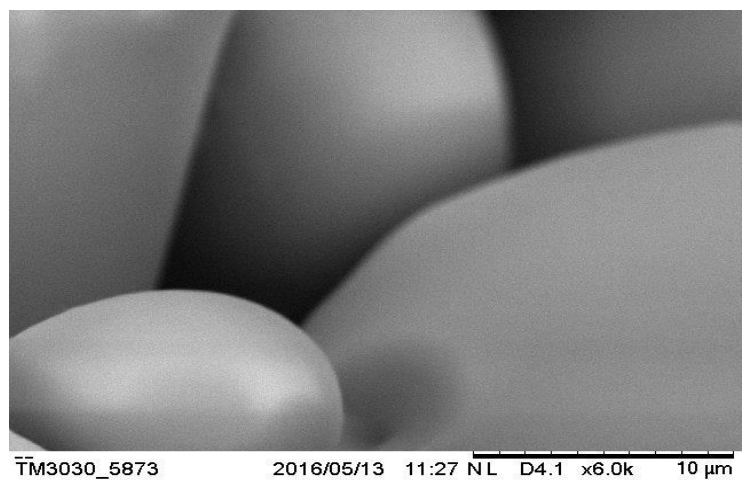

(c)

Figure 1. Scanning electron microscopy (SEM) of starch granules from lemantak. (a) x500, (b) x2000 and (c) x6000

According to Yadav et. al., (2006), the disruption is the result of agglomeration during drying process [10]. In flour industry, disaggregation aimed to improve the flour into free flowing, substantially dustless, more readily "wet-able", packaging, handling and sufficient bulk density to permit measuring without sifting [11]. Apart from this, there were few hollowness observed in sago flour samples indicated the occurrence of gelatinisation during drying processes [12]. Gelatinisation occurs when starch, with the presence of water, is heated at or more than its gelatinization temperature. In addition, moisture content, the variable of interest in this future work, can be one of the factors that affect the aggregation and disaggregation of granular in starch.

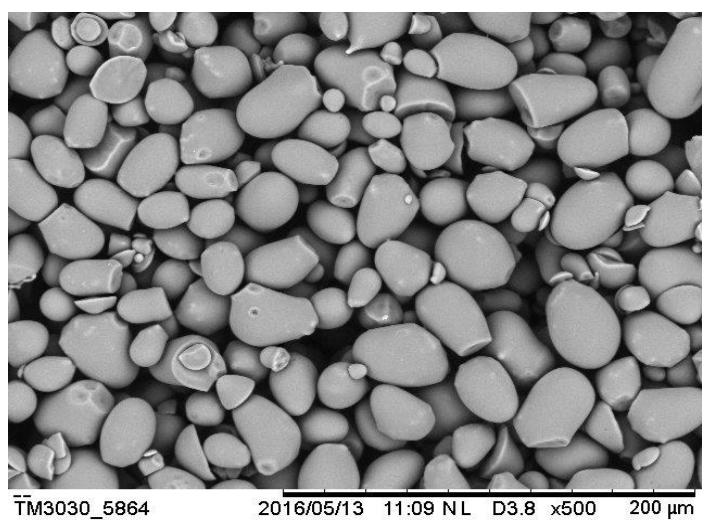

(a)

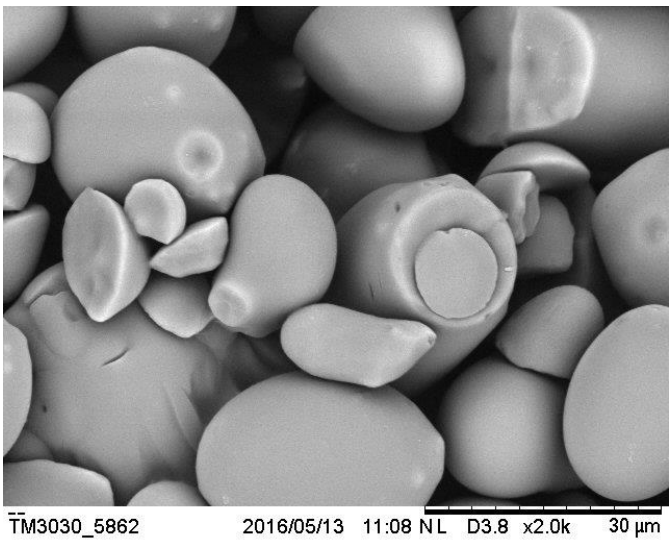

(b)

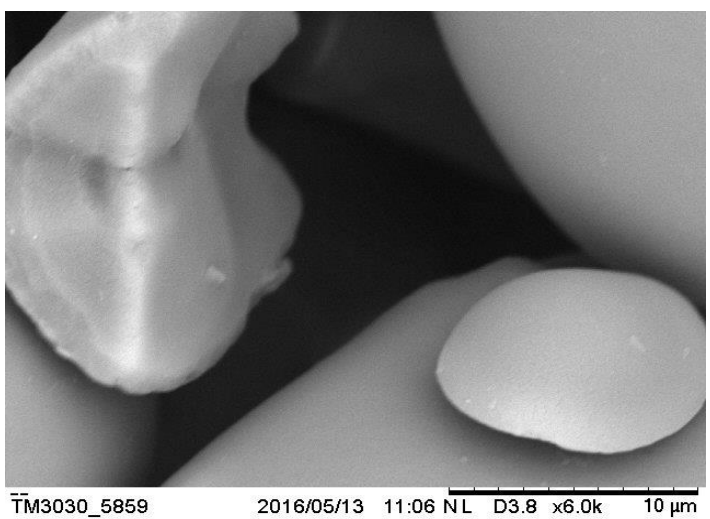

(c)

Figure 2. Scanning electron microscopy (SEM) of starch granules from commercial sago flour. (a) x500, (b) x2000 and (c) $\mathrm{x} 6000$

\subsection{Particle size distribution}


The granule size distribution of commercial sago flour is shown in Figure 3, while the granule size distribution of traditional sago flour is shown in Figure 4. The size of commercial sago flour is in similar manner with traditional sago flour which is in ranged from 1- $100 \mu \mathrm{m}$. The size of commercial sago flour granules were in the range of $15-$ $40 \mu \mathrm{m}$ and the samples displayed a bimodal size distribution with the first mode under $7 \mu \mathrm{m}$ and the second mode between 7 and $100 \mu \mathrm{m}$.

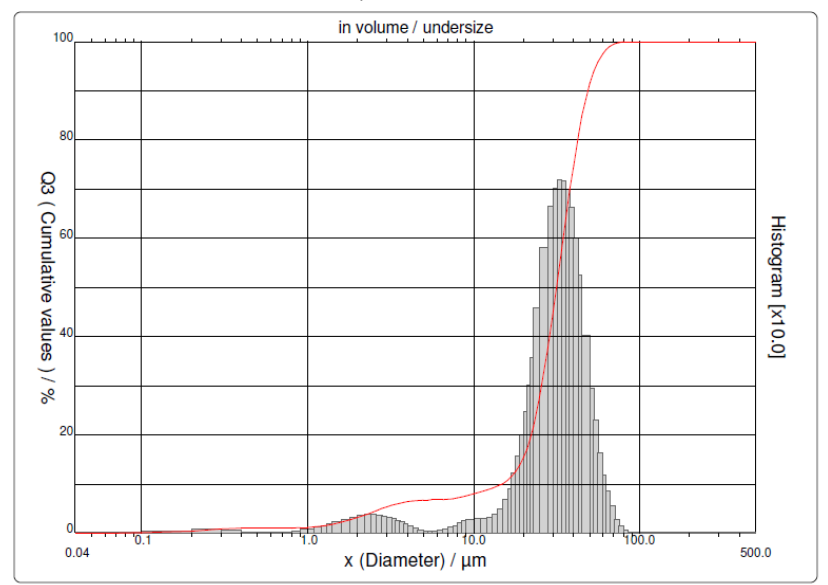

Figure 3. Starch granule size distribution of commercially processed sago starch

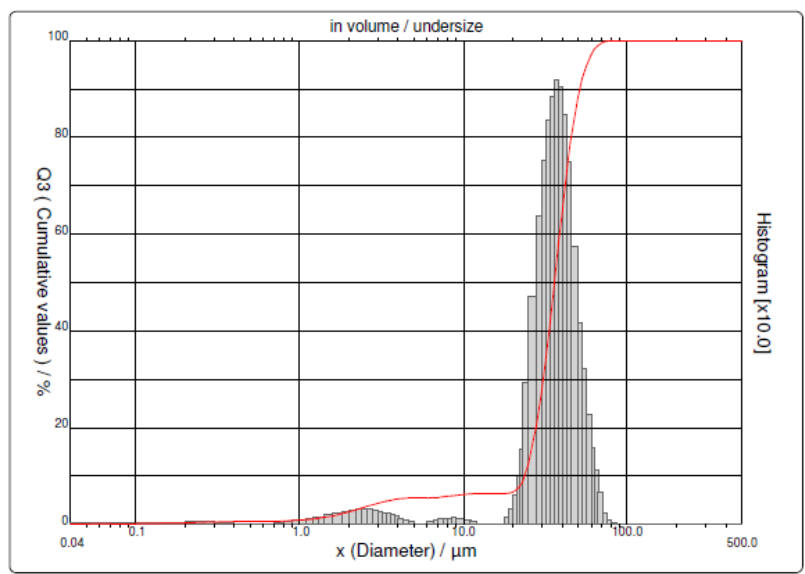

Figure 4. Starch granule size distribution of traditionally processed sago starch (lemantak)

On the contrary, the size of traditional sago flour granules were in the range of and $23-50 \mu \mathrm{m}$ and the samples displayed a trimodal size distribution with the first mode under $7 \mu \mathrm{m}$, the second mode between 7 and $12 \mu \mathrm{m}$, and the third mode between 19 and $100 \mu \mathrm{m}$. Moreover, the diameter at $10 \%, 50 \%$ and $90 \%$ for commercial sago flour are $14.79,31.64$ and $48.90 \mu \mathrm{m}$, respectively while the mean diameter was $31.74 \mu \mathrm{m}$. In contrast, the diameter at $10 \%, 50 \%$ and $90 \%$ for traditional sago flour are 23.61 , 35.98 and $51.36 \mu \mathrm{m}$, respectively while the mean diameter was $35.91 \mu \mathrm{m}$.

Sago starch granules were oval with diameter of $50 \mu \mathrm{m}$. Therefore, it is suggested that the presence of granules with diameter up to $98 \mu \mathrm{m}$ are the result of agglomeration during drying process. According to Njintang et al. (2007), starch with lower the particle size exhibit more hardness, adhesiveness and chewiness, as in food cooked with commercial sago starch [11]. The particle size of lemantak is more than sago flour, hence explain the grainy texture of delicacy made from it.

\subsection{FT-IR}

In order to get information on the possible difference in starch granules structures between commercial and traditional sago starch, their FT-IR were recorded. The spectra obtained from both samples were similar based on the form, but differed in the intensity of the major peaks as shown in Figure 5 and 6.

The changes in functional properties between commercial sago flour and lemantak are attributed to the agglomeration of starch granule [12]. The spectra show high absorption at the wave numbers $854,929,997,1076$, 1149, 1338, 2910 and $3277 \mathrm{~cm}^{-1}$, which confirming the carbohydrate nature of the samples. According to Aboubakar et al. (2008), the bands at 1047 and $1022 \mathrm{~cm}^{-1}$ described the crystalline and amorphous properties of starch, respectively while their ratios indicate the degree of starch order, which were appeared in this study [7].

\section{Conclusion}

The results obtained showed some differences on the structure and properties between commercially and traditionally processed sago starch. The study revealed that sago flours are mainly made of carbohydrate and particularly starch. The granule colour, structure and size varied significantly between each other as the effect of processing method which will be discussed in further work.

\section{Acknowledgements}

This work was supported by FRGS/TK02(04)/1304/2015(210) from Ministry of Higher Education. 


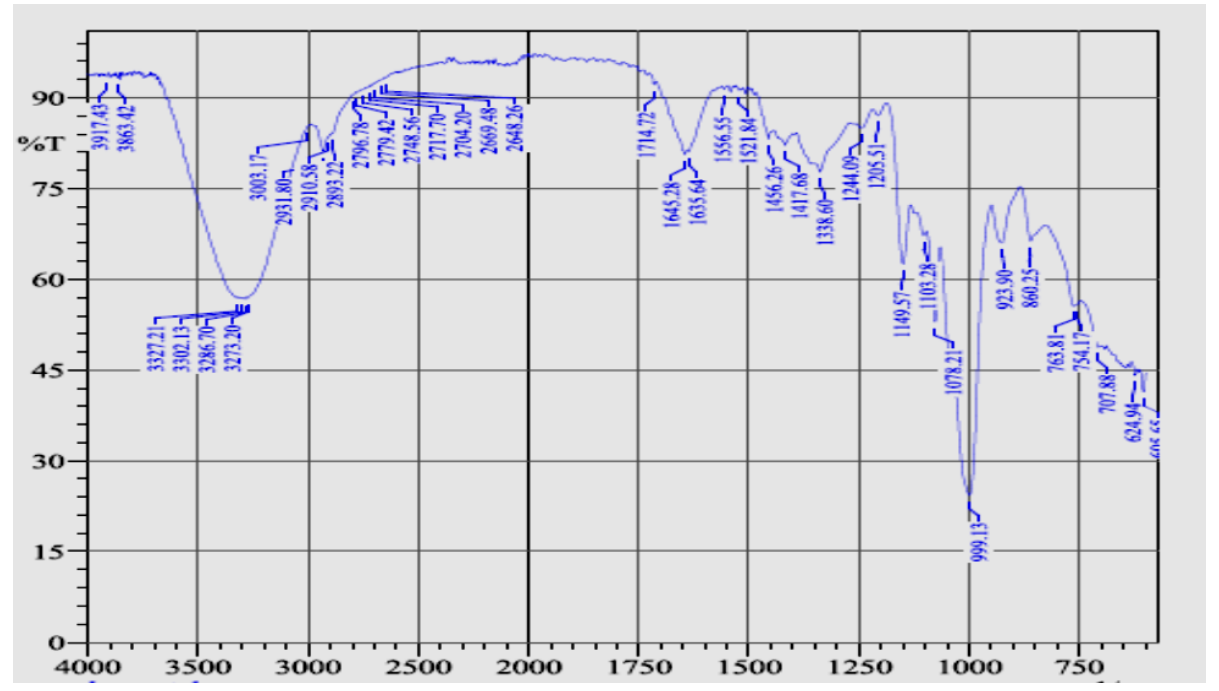

Figure 5. Infrared spectroscopy of commercially processed sago starch

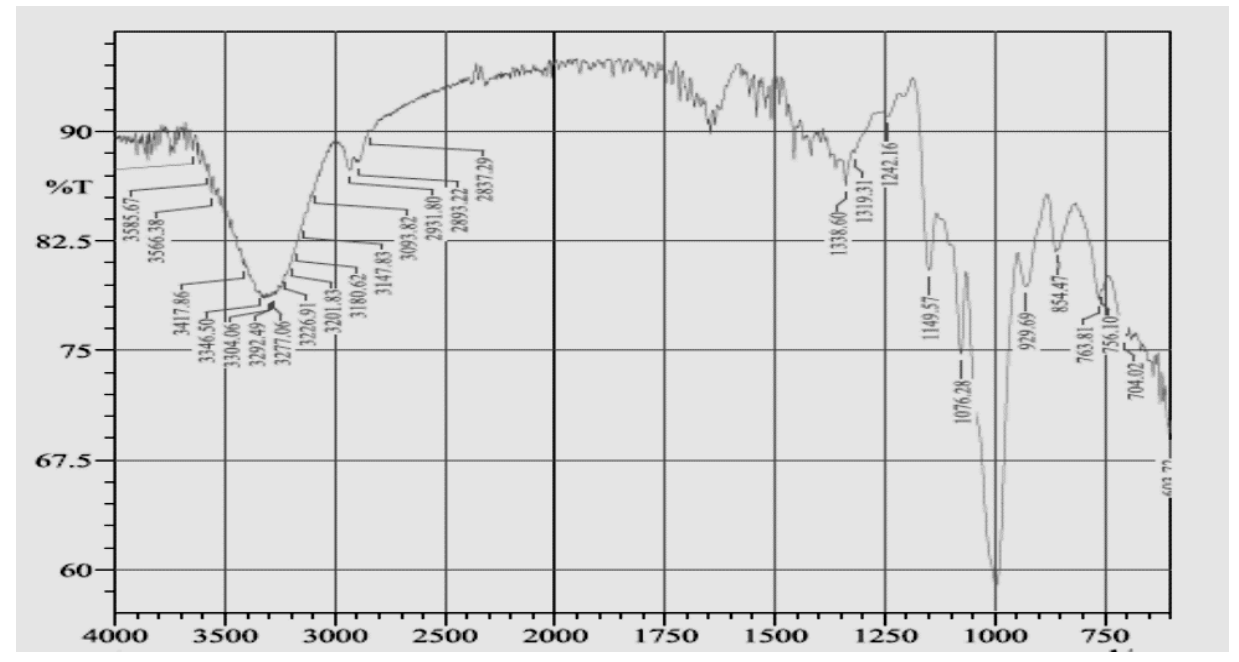

Figure 6. Infrared spectroscopy of traditionally processed sago starch (lemantak)

\section{References}

1. A.A.Karim, A. Pei-Lang Tie, D.M.A. Manan, I.S.M. Zaidul, Comprehensive Reviews in Food Science and Food Safety, (Institute of Food Technologist) 7(2008).

2. Rekha S. Singhal, John F. Kennedy, Sajilata M. Gopalakrishnan, Agnieszka Kaczmarek, Charles J. Knill, Putri Faridatul Akmar, Carbohydrate Polymer 72, 1-20 (2008)

3. Rolf G. Gidlow, North St. Paul, Robert L. Teders, United States Patent Office (1966)

4. Chong Shin, James T. Collins, Mediterranean J. Social Sci. 6(6), 136-144 (2015)

5. Bantacut, T. J. Envi. Earth Sci. 4(21), 202-216 (2014)

6. Chancelle B. Ndangui, Jeremy Petit, Claire
Gaiani, Jean-Mathurin Nzikou, Joel Scher, Food Bioprocess Technol, 7, 3618-3628 (2014)

7. Aboubakar, Y. N. Njintang, J. Scher, C. M. F. Mbofung, J. Food Eng. 86(2), 294-305 (2008)

8. D. Ranjith,P.A.Balakrishnan, National Conferences on Research Advances in Communication, Computation, Electrical Sciences and Structures 2015 (2015)

9. Pei-Lang Tie, Physicochemical properties os sago starch. (2008)

10. Ramesh Yadav, Manisha Guha, R.N. Tharanathan, R.S. Ramteke, Eur Food Res Technol 223, 553-560 (2006)

11. N.Y. Njintang, M.L. Parker, G.K. Moates, C.B. Faulds, A.C. Smith, K.W. Waldron, C.M.F. Mbofung, J. Scher, J. Food Eng. 87, 172-180 (2008) 